\title{
ESTUDO DO PERFIL TÉRMICO DE FORNOS DO TIPO "CAIPIRA" UTILIZADOS PELO SETOR DE CERÂMICA VERMELHA EM PARELHAS NA REGIÃO DO SERIDÓ, RN ${ }^{1}$
}

\begin{abstract}
Áurea de Paula Medeiros e Silva ${ }^{2}$, Rosimeire Cavalcante dos Santos 3 , Renato Vinícius Oliveira Castro ${ }^{4}$, Angélica de Cássia Oliveira Carneiro ${ }^{5}$, Carlos Alberto Paskocimas ${ }^{6}$ e George Santos Marinho ${ }^{7}$

RESUMO - Este trabalho teve como objetivo caracterizar o perfil térmico de fornos tipo "caipira" utilizados pelo setor de cerâmica vermelha em Parelhas, na região do Seridó, RN, visando propor intervenções estruturais que possam colaborar para aumentar a produtividade e qualidade dos produtos, otimizar o consumo de madeira e mitigar as perdas durante o processo de queima. O trabalho foi desenvolvido na Cerâmica Esperança, na cidade de Parelhas, RN. Foram realizados quatro tratamentos com três repetições, sendo a argila o parâmetro utilizado como referência para distinguir os tratamentos. Foram monitorados a quantidade da lenha, a qualidade da telha e o tempo de cada queima. Foram aferidas temperaturas em 15 pontos marcados na superfície da carga enfornada, em intervalos de $30 \mathrm{~min}$ a partir do pré-aquecimento até o final da queima, utilizando um pirômetro de mira a laser. Os resultados indicaram que a madeira utilizada como lenha apresentou densidade sem diferença significativa entre os tratamentos, umidade dentro dos padrões permitidos e consumo heterogêneo, enquanto a argila teve pouca retração linear quando submetida ao fogo e o forno, perfil térmico heterogêneo. O parâmetro do fio, que é utilizado como referência para o controle da queima, foi significativo, embora com oscilações diferenciadas, razão por que não deve ser o único critério para finalização do processo de queimas. A parte central do forno foi a área que atingiu maiores temperaturas de maneira homogênea, com maior concentração de produtos de primeira qualidade; a curva de temperatura ideal foi do tratamento 1 , com uma média de $18,66 \%$ de produto de primeira qualidade, com temperatura de $100{ }^{\circ} \mathrm{C} \mathrm{a} 400{ }^{\circ} \mathrm{C}$.
\end{abstract}

Palavras-chave: Indústria Cerâmica; Eficiência térmica; Fornos do tipo "caipira".

\section{STUDY OF THERMAL PROFILE OF “CAIPIRA” TYPE FURNACES USED BY THE RED CERAMIC INDUSTRY IN PARELHAS, SERIDÓ REGION, RN}

\begin{abstract}
This study aimed to evaluate the thermal profile of "caipira" type furnaces, used by the red ceramic industry in Parelhas, region of Seridó- $R N$, in order to suggest structural interventions that may cooperate with the increase of the products productivity and quality, optimize wood consumption and reduce losses during the burning process. The study was conducted in the Esperança brickyard located in Parelhas-RN, Brazil. Four treatments were conducted with three replications, and clay was the parameter used as a reference to distinguish treatments. The wood quantity, quality of tile and burning time were monitored. Temperature measurements were made at 15 points in the surface of the burning charge into the furnace, and the temperatures were taken every 30 minutes, from the preheating to the end of the burning process, using a laser pyrometer. The data
\end{abstract}

\footnotetext{
${ }^{1}$ Recebido em 26.02.2014 aceito para publicação em 10.06.2015

${ }^{2}$ Universidade Federal do Rio Grande do Norte, Mestrado em Ciências Florestais, Unidade Acadêmica Especializada em Ciências Agrárias, Escola Agrícola de Jundiaí, Macaíba, RN, Brasil. E-mail:<aurea-sofia@hotmail.com>.

${ }^{3}$ Universidade Federal do Rio Grande do Norte, Unidade Acadêmica Especializada em Ciências Agrárias, Escola Agrícola de Jundiaí, Macaíba, RN, Brasil. E-mail:<meire_caico@yahoo.com.br>.

${ }^{4}$ Universidade Federal de São João Del-Rei, Departamento de Ciências Agrárias, Campus Sete Lagoas CSL, Sete Lagoas, MG

- Brasil.E-mail:<castrorvo@ymail.com>.

${ }^{5}$ Universidade Federal de Viçosa, Departamento de Engenharia Florestal, Viçosa, MG - Brasil. E-mail:<cassiacarneiro@ufv.br> .

${ }^{6}$ Universidade Federal do Rio Grande do Norte, Centro de Tecnologia, Departamento de Engenharia de Materiais, Natal, RN - Brasil. E-mail: <paskocimas@uol.com.br>.

${ }^{7}$ Universidade Federal do Rio Grande do Norte, Centro de Tecnologia, Departamento de Engenharia Mecânica, Natal, RN

- Brasil.E-mail:<marinho@hotmail.com>.
} 
showed that the wood presented density with no significant difference between results, humidity according to allowed standards and heterogeneous consumption, while clay had little linear retraction when submitted to fire and the furnace had heterogeneous thermal profile. The wire parameter, used as reference for the burning control, was significant, although with different oscillations, being the reason why it should not be the only criterion to the finalization of the burning process. The furnace central part was the area that reached higher temperatures and more evenly, with the highest concentration of top quality products; the ideal temperature curve was treatment 1 , which obtained average of $18.66 \%$ of top quality product, with temperature ranging from 100 to $400^{\circ} \mathrm{C}$.

Keyword: Ceramic industry; Thermal efficiency; "Caipira" type furnaces.

\section{INTRODUÇÃO}

No Estado do Rio Grande do Norte a indústria de cerâmica vermelha está distribuída nas mesorregiões Oeste Potiguar, Centro Potiguar, Agreste Potiguar e Leste Potiguar. O setor ceramista no Estado sempre se configurou como segmento que gera grande impacto ao meio ambiente, desencadeados principalmente pela extração e consumo significativo de matérias primas utilizadas em sua produção.

A indústria de cerâmica no RN utiliza, em grande parte, a lenha como fonte de combustível, o que vem agravando os problemas ambientais no Estado. A remoção de lenha num espaço geográfico como a Caatinga tem comprometido a estabilidade do ecossistema tendo influência direta sobre a fauna e flora da região, e isso reflete a atual situação da região visto que a lenha utilizada é extraída da mata nativa, e que no Estado ainda não se vê iniciativa de implementação de áreas de reflorestamento ou manejo suficiente para abastecer a demanda da produção.

A indústria de cerâmica vermelha é uma atividade econômica, que vem diversificando seu produto e aumentando cada vez mais seu mercado consumidor (CARVALHO, 2001). Isso mostra que o quadro atual é preocupante considerando que os tipos de fornos utilizados, em sua grande maioria, ainda permanecem os mesmos de décadas, com baixa eficiência, com um consumo de combustível elevado e tendo como resultados uma quantidade significativa de produtos caracterizados como de segunda qualidade, e com uma grande porcentagem de perdas ao longo de toda sua produção.

Para a indústria de cerâmica vermelha o controle dos parâmetros de queima nos fornos é de fundamental importância para reduzir as perdas e obter um produto final de qualidade. Entretanto, as pequenas empresas de cerâmica ainda não apresentam as condições ideais de produção, e alegam que isso não ocorre em virtude, principalmente, dos custos elevados para uma estruturação adequada. Com isso, ainda operam com técnicas inadequadas em seus sistemas de queima, deixando de realizar o controle tecnológico eficiente, funcionando de maneira empírica, o que resulta no aumento dos custos na produção e no consumo de insumos, e influenciam a qualidade do produto final.

No Estado do Rio Grande do Norte, especialmente na região do Seridó ainda são predominantes os fornos do tipo "caipira" com processo de produção artesanal, o que contribui significativamente na baixa qualidade dos produtos e nos desperdícios gerados ao longo de toda produção. Com essa situação, e considerando a não existência de estudos nesse aspecto urge a necessidade de serem realizados trabalhos que tratem do perfil térmico dos fornos ou ainda estudos que estabeleçam a relação entre o controle empírico adotado no processo e as temperaturas alcançadas durante a queima do forno, características e consumo de lenha e qualidade dos produtos. Com o desenvolvimento desses estudos, acredita-se ser possível tomar decisões adequadas sobre alterações estruturais dos fornos de modo que seja possível atender as normas exigidas de qualidade do produto, bem como reduzir o desperdício.

Diante do exposto, o trabalho possui como objetivo caracterizar o perfil térmico de fornos tipo "caipira" utilizados pelo setor de cerâmica vermelha em Parelhas, na região do Seridó/RN, visando propor intervenções estruturais que possam colaborar para aumentar a produtividade e qualidade dos produtos, otimizar o consumo de madeira e mitigar as perdas existentes durante o processo de queima.

\section{MATERIAL E MÉTODOS}

O trabalho foi desenvolvido na Cerâmica Esperança, indústria localizada no município de Parelhas/RN que tem uma produção de aproximadamente 800 milheiros/ 
mês, sendo 97\% referente a telhas. Em seu processo de produção a empresa realiza, em média, cinco queimas semanais, sendo a madeira o recurso energético exclusivo utilizado para a etapa de queima dos produtos, com consumo médio de $100 \mathrm{~m}^{3}$ por semana em quatro fornos do tipo "Caipira".

Os fornos utilizados na pesquisa foram construídos com tijolos comuns, e foram dotados de uma caixa de abastecimento destinada à acomodação das peças cerâmicas a serem queimadas, além de 8 câmaras de combustão (base do forno) por onde ocorre a entrada de ar conforme apresentado na Figura 1a. O sistema de distribuição de calor ocorre no piso que é constituído por tijolos de oito furos, visando a passagem dos gases de combustão. Para construção de paredes foram utilizados tijolos maciços espaçados. Os gases de combustão seguem uma trajetória ascendente, passando pelas peças de cerâmica que estão sendo cozidas, e atingem o topo, onde não há cobertura de alvenaria.

Os fornos utilizados no estudo apresentam as seguintes dimensões: 9,95 $\mathrm{m}$ de largura $\times 3,02 \mathrm{~m}$ de comprimento $\times 2,26 \mathrm{~m}$ de profundidade; as câmaras de combustão apresentam dimensões de $54 \mathrm{~cm}$ de largura $\times 49 \mathrm{~cm}$ de altura $\times 372 \mathrm{~cm}$ de profundidade. Esses fornos acomodam aproximadamente 37 a 42 mil telhas por queima. Não possuem grelhas na estrutura das câmaras de combustão, sendo que as cinzas são retiradas (manualmente) ao final de cada ciclo.

O processo de enchimento de forno é feito por uma abertura na parte da frente, que em seguida é fechada com barro. Após o fechamento dessa entrada dá-se início ao processo de queima, e ao final desse processo inicia-se o resfriamento dos produtos cerâmicos; em seguida pode-se realizar a retirada dos produtos fabricados.

Esses fornos apresentam baixo custo de construção e de manutenção de operação, porém são fornos com baixíssima eficiência energética. $O$ forno caipira não possui nenhum controle efetivo de temperatura e de vazão de ar durante o processo, para proceder às intervenções na combustão, visando um melhor aproveitamento do calor gerado pela queima da biomassa. A avaliação do processo se baseia no parâmetro do fio de cobre (método empírico). Esse método consiste em esticar um fio de cobre sobre a superfície do forno (sobre as telhas) conforme apresentado na Figura 1b, e à medida que ocorre a transferência de calor para

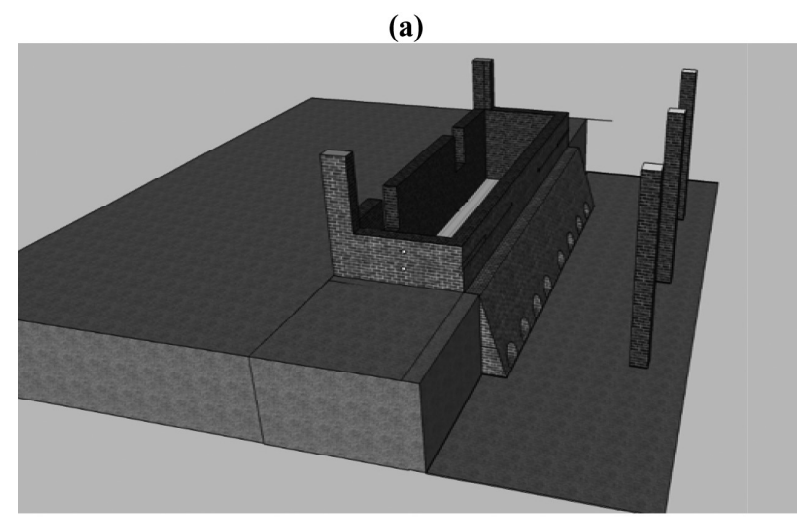

(b)

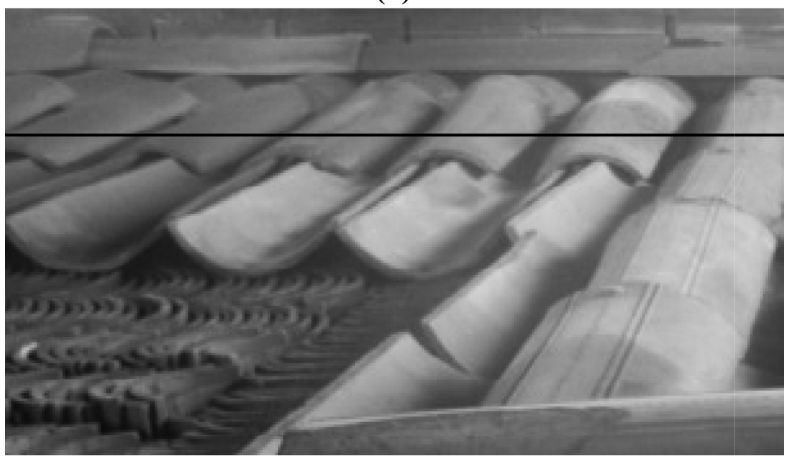

(c)

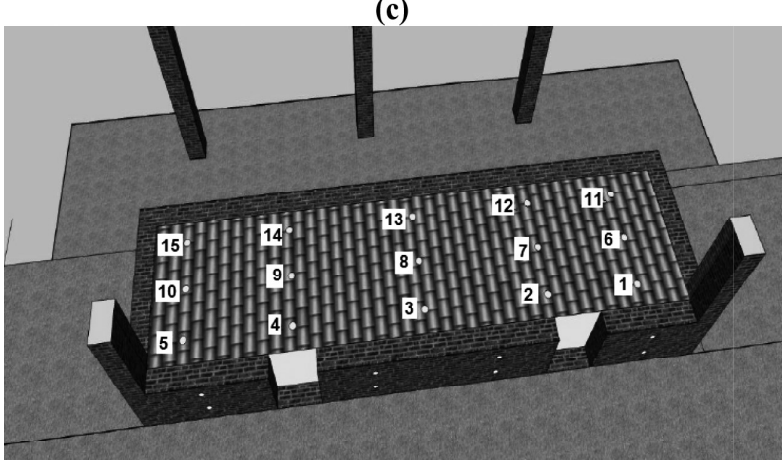

Figura 1 - Esquema do forno tipo "caipira" (a), ilustração do fio de cobre sobre a superfície do forno (b) e pontos de amostragem para aferição das temperaturas ao longo da superfície da carga (c).

Figure 1-Scheme of the furnace type "caipira" (a), illustration of the copper wire on the surface of the oven (b) and the sampling points for the measurement of temperatures along the surface of the load (c).

as telhas, o fio de cobre, que também recebe calor, dilata. A distância entre o fio o as telhas, que inicialmente é zero, começa a aumentar. Quando a distância chega a aproximadamente $6 \mathrm{~cm}$ os operadores dos fornos interrompem o processo (final da queima) e então inicia-se

\section{sitif}

Revista Árvore, Viçosa-MG, v.39, n.5, p.963-972, 2015 
o resfriamento. No entanto, esse procedimento baseia-se na experiência do operador do forno e dessa forma, nem sempre se consegue o melhor aproveitamento do processo de queima.

Foram utilizados 4 tratamentos, sendo esses, quatro diferentes lotes de argila, diferidos após as caracterizações por meio de análise granulométrica. Para cada tratamento, foram utilizadas três repetições, totalizando 12 unidades experimentais (queimas).

Foram distribuídos 15 pontos para aferições de temperatura, de maneira equidistante, sendo 5 fileiras com 3 pontos em cada, separados $1,54 \mathrm{~cm}$ entre eles (Figura 1c), sendo monitorados durante toda a queima. Esses pontos foram marcados com um giz (material que não apaga em altas temperaturas) sobre a carga de cerâmicas no momento da finalização do enfornamento das telhas, em cada queima. As tomadas de temperatura nos pontos foram feitas em intervalos de 30 minutos a partir do pré-aquecimento (inicio da queima) até o final da queima, utilizando-se pirômetro com mira a laser nos pontos indicados. O tempo de queima, também foi determinado durante todo o processo (préaquecimento, queima e resfriamento) de todas as queimas.

Procedeu-se a qualificação das telhas após as queimas em cinco classes, sendo: produtos de primeira qualidade, segunda qualidade, terceira qualidade, produtos mal queimados (chocolates), e desperdícios (telhas quebradas, empenadas ou trincadas), de acordo com o procedimento padrão da empresa para essa qualificação.

Realizou-se o monitoramento do abastecimento de lenha desde o pré-aquecimento, até a finalização da queima, sendo determinada a quantidade de vezes em que o forno foi abastecido durante todo o processo, pelo volume da área das câmaras de combustão. Além disso, também foi avaliada a qualidade da lenha utilizada para a queima, originadas das espécies Mimosa tenuiflora (Willd.) Poiret (Jurema preta) e Prosopis juliflora (Sw) DC (Algaroba).

Para determinação da densidade básica e teor de umidade da lenha, foram coletadas amostras da madeira na pilha de lenha que se encontrava no pátio da cerâmica. Foram retirados discos com $4 \mathrm{~cm}$ de espessura, sendo duas amostras de discos de menor diâmetro de madeira, duas médias e duas grossas, totalizando 6 amostras em cada queima. Em seguida, determinou-se a massa de cada disco, que foi devidamente identificado em campo, para serem armazenadas em sacos plásticos e levadas para o laboratório de análises de madeira da Escola Agrícola de Jundiaí da Universidade Federal do Rio Grande do Norte para realização das análises de densidade básica e umidade da madeira.

A determinação da densidade básica foi realizada de acordo com o método de imersão em água, descrito por Vital (1984). Os valores foram calculados a partir da média aritmética das densidades das respectivas amostras coletadas em campo. Para determinação do teor de umidade, utilizou-se o método da estufa, onde as amostras foram colocadas em estufa a $103^{\circ} \mathrm{C}$ até peso constante e calculadas de acordo com Silveira et al. (2013). Os valores de densidade da madeira utilizada nos quatro tratamentos foram submetidos à análise de variância $(\alpha=0,05)$.

A interpretação do perfil térmico deu-se por meio de análise descritiva dos dados, elaboração de curvas médias de temperaturas e análises de regressão linear. A interpretação do parâmetro de distância do fio de cobre, como padrão de referencia para a finalização da queima das cerâmicas (após atingir $6 \mathrm{~cm}$ ), foi realizada por meio da relação gráfica com o tempo de queima e temperatura máxima atingida e análise de regressão linear.

\section{RESULTADOS}

A densidade básica média da madeira utilizada em todos os tratamentos foi de $0,68 \mathrm{~g} . \mathrm{cm}^{-3}$, sendo esse valor interessante para a combustão, uma vez que quanto maior a densidade da madeira, maior a quantidade de energia estocada. Nos tratamentos $1\left(0,64\right.$ g. $\left.\mathrm{cm}^{-3}\right) \mathrm{e}$ $4\left(0,67 \mathrm{~g} . \mathrm{cm}^{-3}\right)$ observou-se valores de densidade básica da madeira inferiores aos dos tratamentos $2\left(0,70 \mathrm{~g} \cdot \mathrm{cm}^{-3}\right)$ e $3\left(0,70 \mathrm{~g} \cdot \mathrm{cm}^{-3}\right)$. Estes valores não diferenciaram significativamente pelo teste $\mathrm{F}$ da análise de variância $(\mathrm{p}>0,05)$.

Para o tratamento 1 observou-se o maior valor médio de umidade da madeira $(30,08 \%)$, sendo significativamente superior aos demais tratamentos (abaixo de 20\%). Observou-se que o tratamento 4 apresentou o menor teor de umidade da madeira $(13,66 \%)$. É importante salientar que a determinação do teor de umidade da madeira é de grande importância, uma vez que essa característica está associada a perdas de energia durante a combustão, uma vez que é necessário fornecer 
calor para a retirada da água presente na madeira. Sendo assim, quanto maior teor de umidade da madeira, maior a quantidade de energia necessária para retirar a água, o que implica em perda de material que será efetivamente queimado. Os resultados encontrados são considerados satisfatórios, e dentro dos padrões permitidos, pois a umidade de equilíbrio da madeira ficou próxima ao ponto de saturação das fibras, de $22 \%$ a $30 \%$.

Os valores médios do abastecimento da lenha nos tratamentos 2 e 4 não apresentaram diferenças significativas, obtendo os maiores consumos de lenha durante a queima, seguido do tratamento 1 , e do tratamento 3 que diferem dos demais.

Os resultados de granulometria das amostras revelam que o tratamento 1 teve significativa presença de argila $(12 \%)$, e silte $(81 \%)$, o tratamento 2 obteve $20 \%$ de argila e $77 \%$ de silte, o 3 apresentou $25 \%$ e $70 \%$ e o tratamento $4,23 \%$ e $78 \%$ para argila e silte, respectivamente. A presença de partículas maiores faz com que a retração das telhas quando submetidas a altas temperaturas seja menor, considerando que quanto menor for a granulometria maiores serão a plasticidade e a retração.

Na Figura 2 são apresentados os valores médios de temperatura aferidos na superfície do forno caipira ao longo do processo de queima da telha para os tratamentos 1, 2, 3, e 4. De acordo com a Figura 2, observa-se que a média do tempo de queima na produção das telhas foi de 825 minutos, sendo que para os tratamentos 1, 2, 3 e 4 foram de 870, 910, 900 e 620 minutos, respectivamente.

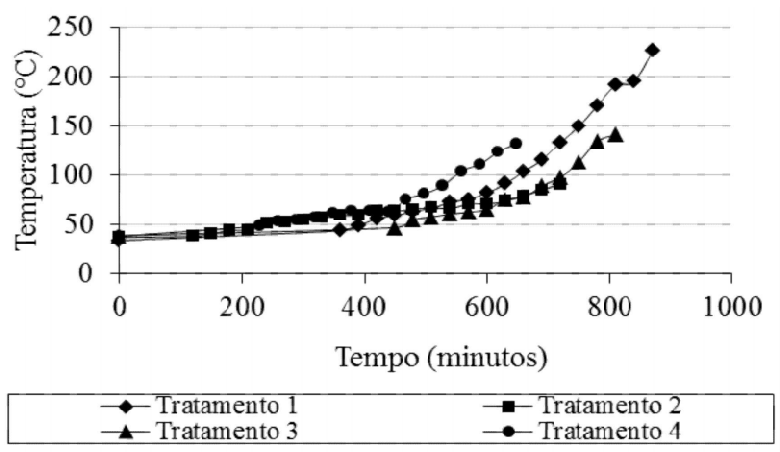

Figura 2 - Temperaturas médias dos tratamentos 1, 2, 3 e 4 durante o ciclo de queima.

Figure 2-The average temperatures of the treatments 1, 2, 3 and 4 during the burning cycle.
Na Figura 3 são apresentadas as equações lineares que relacionam a distância do fio e o tempo de queima (a), e a distância do fio com a temperatura nos fornos (b) na superfície do forno.

Observa-se na Figura 3 que ao aumentar a temperatura e o tempo, aumentam também a distância do fio em todos os tratamentos. $\mathrm{O}$ tratamento 1 atingiu maior temperatura e maior distância do fio para as telhas com relação aos demais tratamentos.

$\mathrm{Na}$ Figura 4 são apresentadas as equações de temperatura média em função do tempo para os quatro tratamentos, utilizando uma equação linear quadrática.

Na Figura 5 é apresentada a relação entre a porcentagem de telhas de primeira qualidade com a temperatura máxima atingida no forno e a taxa média de aquecimento para os pontos de medição 7, 8 e 9, localizados na região central da superfície do forno.

\section{DISCUSSÃO}

As médias das temperaturas observadas durante a queima nos tratamentos não ultrapassaram $250^{\circ} \mathrm{C}$, sendo respectivamente $230^{\circ} \mathrm{C}, 170^{\circ} \mathrm{C}, 140^{\circ} \mathrm{C}$ e $170^{\circ}$ para os tratamentos 1, 2, 3 e 4 (Figura 2). Nos quatros tratamentos, observou-se uma grande variação de temperatura entre os quinze pontos durante toda a queima, o que indica grande perda de energia entre a câmara de combustão e a parte superior da carga. Esses resultados estão de acordo com os estudos do EELA (2012) que observou que há distribuição deficiente de calor nas diversas regiões do forno "Caipira".

Conforme pode ser observado, as temperaturas alcançadas nos 4 tratamentos foram distintas, assumindo, inclusive particularidades em relação ao tempo decorrido durante o processo. Esses resultados indicam a heterogeneidade do processo de queima em fornos do tipo "caipira" em função da sua estrutura e falta de controle. Além disso, pode ter sido, também, influenciado pelo tipo de combustível utilizado na queima, e as condições climáticas. $O$ tratamento 1 obteve maior temperatura de queima, sendo utilizadas as lenhas de jurema e algaroba, e os tratamento 2, 3 e 4 obtiveram menor temperatura sendo usado apenas lenha de algaroba, evidenciando-se que nesses dias em que foram feitos os experimentos ventava forte, o que provavelmente influenciou na temperatura. $O$ tratamento 4 atingiu o menor tempo de queima e a lenha usada obteve menor umidade entre os tratamentos.

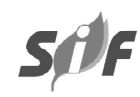

Revista Árvore, Viçosa-MG, v.39, n.5, p.963-972, 2015 
Outro fator que pode ter contribuído para a oscilação da temperatura foi a umidade e a densidade da madeira utilizada nas queimas que foram distintas nos 4 tratamentos. O tratamento 4 obteve menor tempo de queima e a madeira utilizada, a algaroba, foi a que teve menor umidade. Para Freitas (2007) as
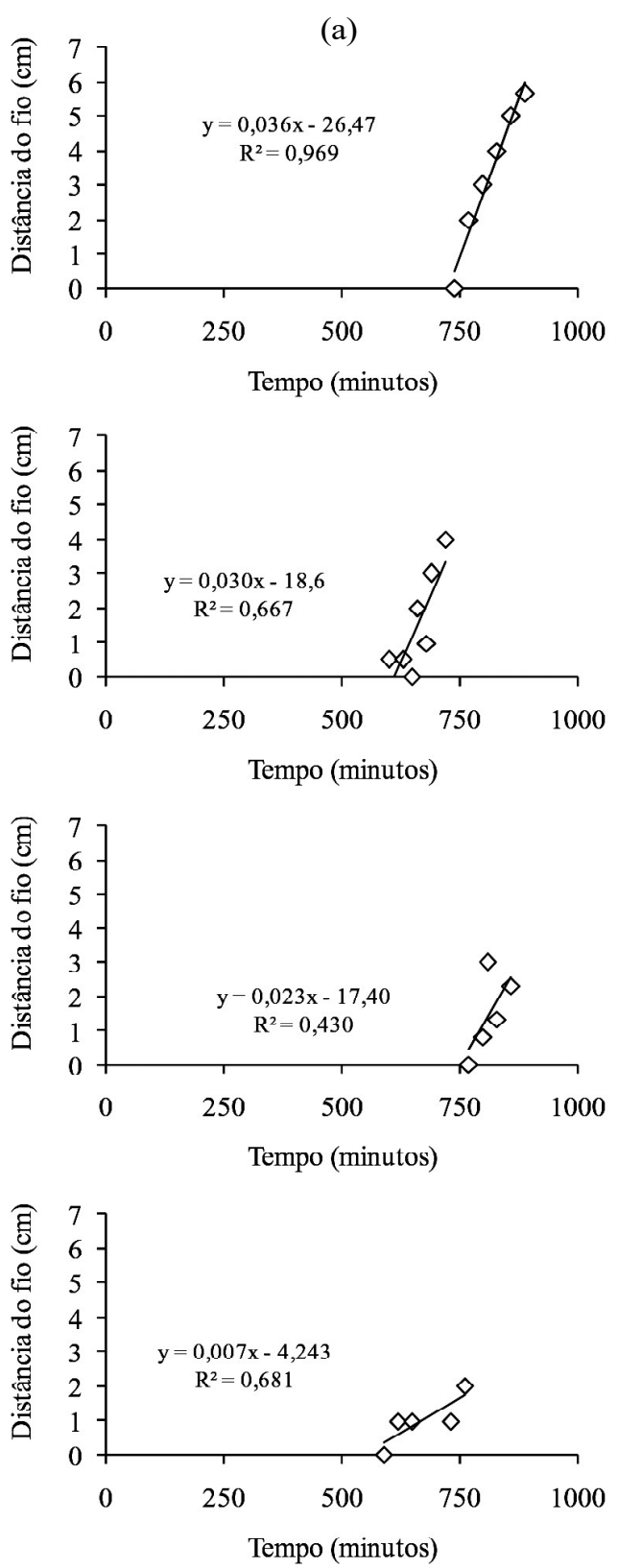

diferenças fundamentais na temperatura em fornos cerâmicos são as características do forno, dimensão, natureza do combustível, localização, sistema de controle e o modo de deslocamento da carga no interior do forno, bem como a queima é conduzida pelos operadores.
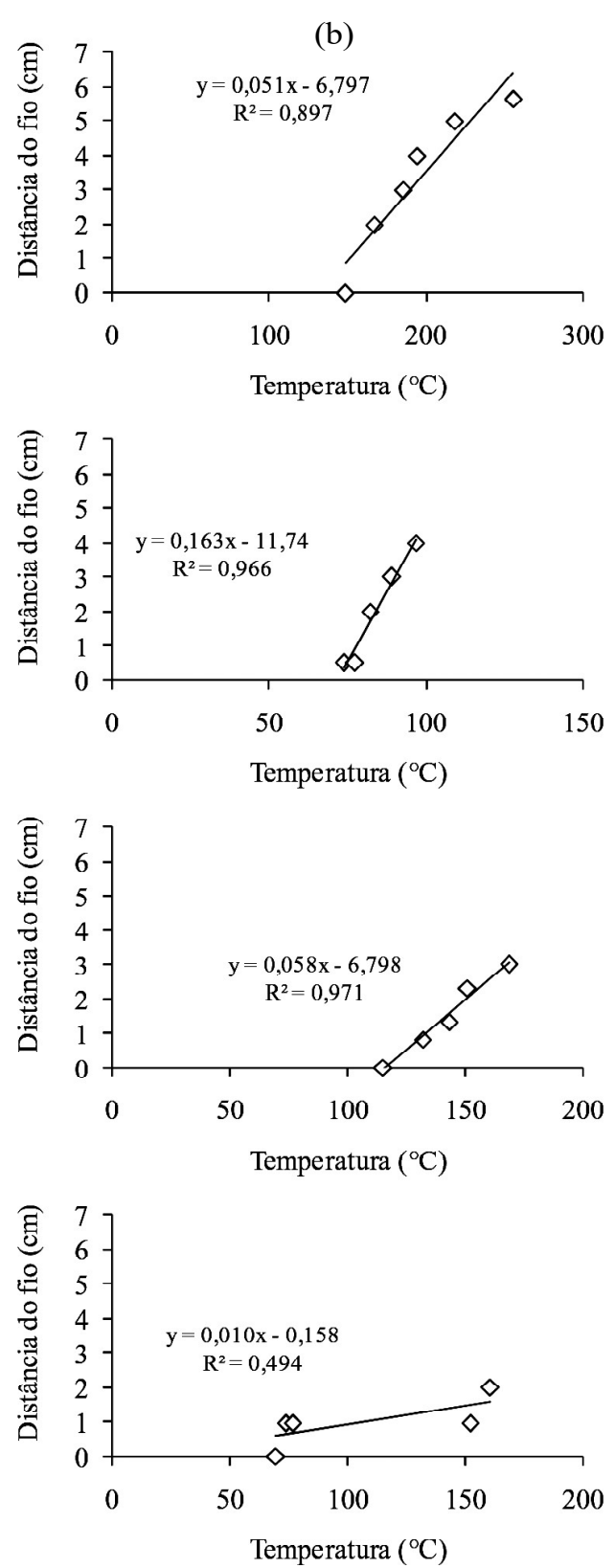

Figura 3 - Relação entre a distância do fio e o tempo de queima (a) e a temperatura (b), em todos os tratamentos avaliados. Figure 3 - The relationship between the distance from the wire and burning time (a) and temperature (b) for all treatments.

Revista Árvore, Viçosa-MG, v.39, n.5, p.963-972, 2015 


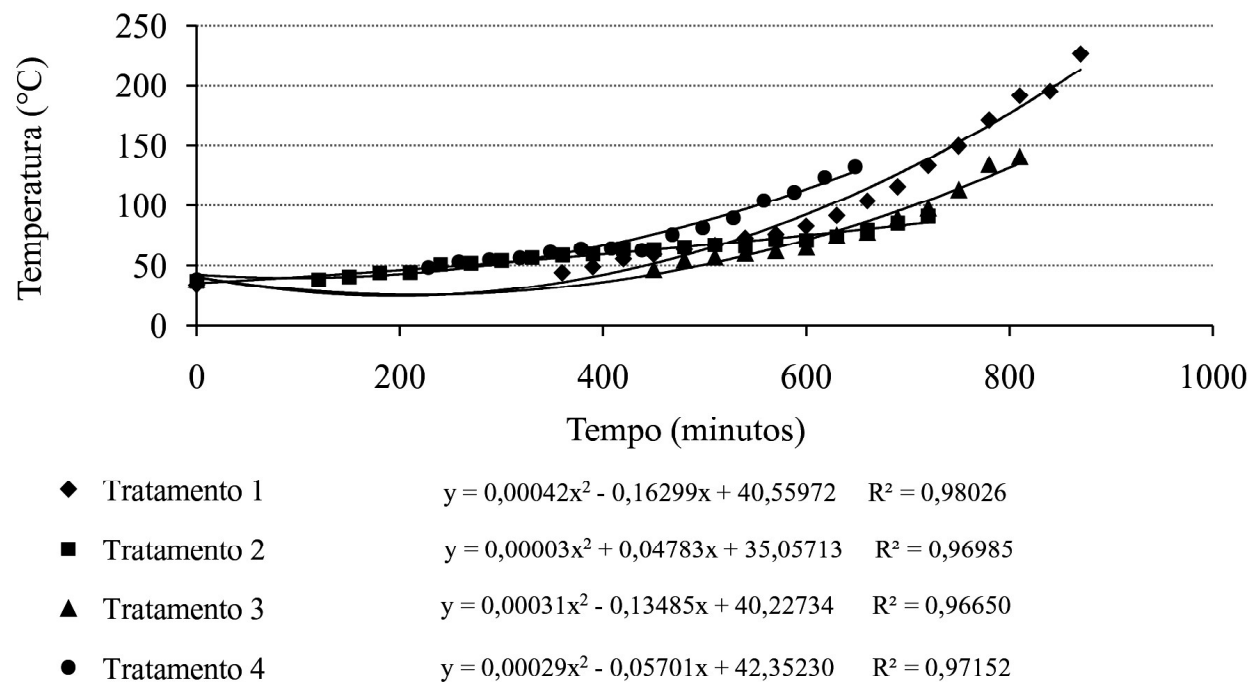

Figura 4 - Equações de temperatura média em função do tempo dos tratamentos 1 a 4 , utilizando uma equação linear quadrática. Figure 4 -Equations of average temperature versus time for treatments 1 to 4 using a linear quadratic equation.

De acordo com Queiroz et al. (1988), para conduzir a queima de modo adequado, é fundamental visualizar o que nela ocorre, o que demanda preferencialmente o monitoramento e controle das temperaturas, para que a curva de queima real se aproxime ao máximo da curva ideal, evitando-se a avaliação visual pela cor da peça processada, que acarreta uma menor variabilidade de temperatura.

De acordo com a tendência apresentada na Figura 3, observa-se que com o aumento da temperatura na queima inicia-se um distanciamento da superfície do forno com o fio em todos os tratamentos, e isso ocorre porque o aumento de temperatura afeta significativamente a retração linear das telhas, pois quanto maior a temperatura, maior é a retração linear da argila.

Nos 4 tratamentos a análise granulométrica mostrou que a argila utilizada é constituída em grande parte de partículas maiores, tendo uma composição de areia e silte bem maior do que de argila.

Contudo a argila mais plástica possui menor estabilidade térmica, maior perda de massa e maior retração depois de submetidas à queima. Uma prática industrial comum tem sido misturar diferentes tipos de argilas a fim de obter uma formulação ideal, para que a perda pela exposição ao fogo e a retração não sejam excessivamente elevadas, e não prejudiquem a estética e a qualidade do produto. A argila utilizada por ter apresentado granulometria maior, indica porque a oscilação do fio com a carga no tratamento 2,3 e 4 foi pequena, enquanto o tratamento 1 que tinha uma maior presença de argila expandiu mais.

Observou-se que com o aumento da temperatura houve um distanciamento significativo do fio com carga enfornada em todos os tratamentos, com variação de oscilações diferenciadas. O método do fio utilizado para o controle de queima em fornos do tipo "caipira" é considerado um método empírico, pois não existe nenhum instrumento que auxilie o controle da distância do fio, ou regule o aumento ou a diminuição da temperatura do forno.

De acordo com o relatório EELA (2012), o fio de cobre é atualmente, o único indicador para controle do processo.

A distância do fio entre o produto cerâmico ao final do processo deve ser próximo de $6 \mathrm{~cm}$, e isso ocorreu, apenas no tratamento 1 , demonstrando que cada argila tem uma capacidade distinta em reação a retração, evidenciando que esse não é o parâmetro ideal para finalização do processo de queimas de produtos cerâmicos em fornos do tipo caipira.

As temperaturas obtidas na superfície do forno não representam a temperatura ao longo do forno todo, pois, as temperaturas obtidas na superfície são mais 
Tratamento 1

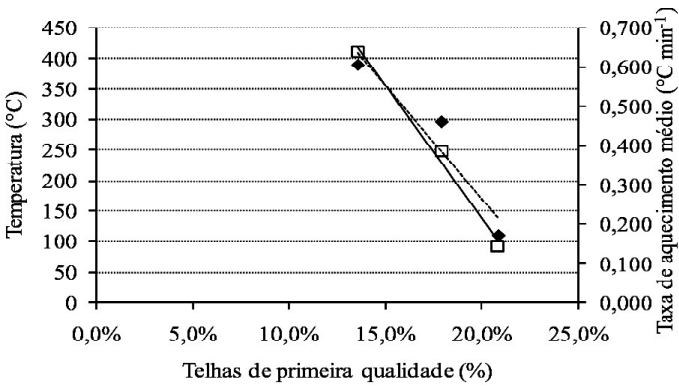

$$
\begin{array}{lcc}
- \text { Temperatura média }\left(\mathrm{C}^{\circ}\right) & \begin{array}{c}
\mathrm{y}=-3721, \mathrm{x}+914,1 \\
\mathrm{R}^{2}=0,912
\end{array} \\
\begin{array}{c}
\mathrm{y}=-6,760 \mathrm{x}+1,569 \\
\mathrm{R}^{2}=0,990
\end{array}
\end{array}
$$

Tratamento 3

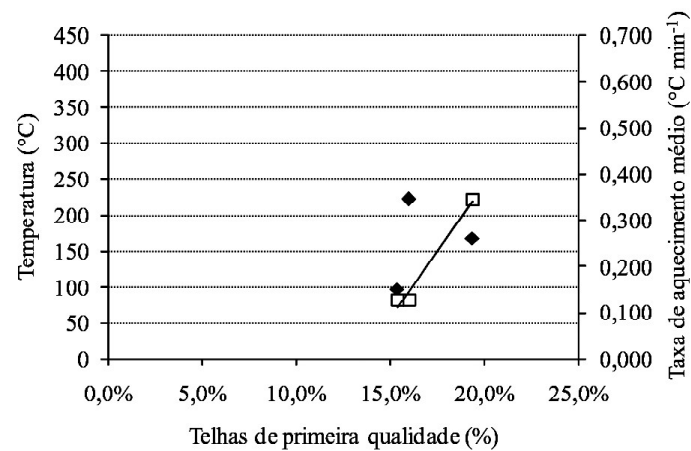

- Temperatura média $\left(\mathrm{C}^{\circ}\right)$

$\square$ Taxa de aquecimento médio $\left({ }^{\circ} \mathrm{C}\right.$ min- $\left.^{1}\right) \quad \mathrm{y}=5,819 \mathrm{x}-0,78$
Tratamento 2

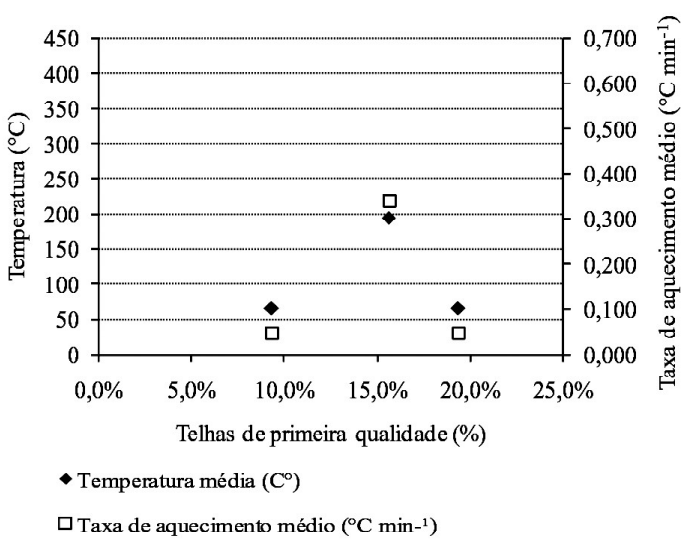

Tratamento 4

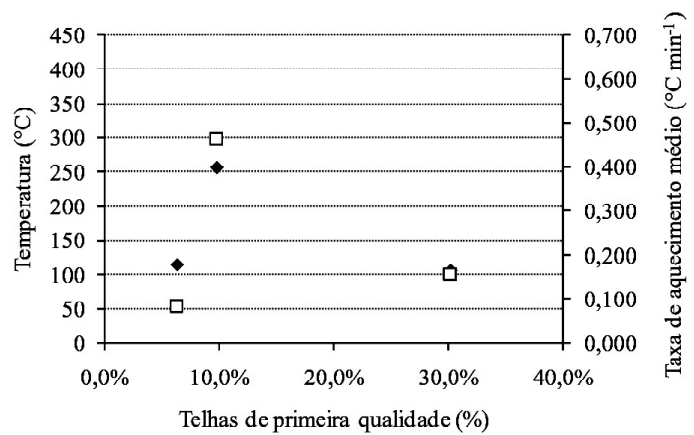

- Temperatura média $\left(\mathrm{C}^{\circ}\right)$

$\square$ Taxa dc aquecimcnto mćdio $\left({ }^{\circ} \mathrm{C}\right.$ min- $\left.^{-1}\right)$

Figura 5 - Relação entre a porcentagem de telhas de primeira qualidade com a temperatura máxima atingida na superfície do forno e a taxa média de aquecimento dos pontos de medição 7,8 e 9 , localizados na região central da superfície do forno. As equações apresentadas foram significativas pelo teste $F(p<0,05)$.

Figure 5 -Relationship between the percentage of first quality tiles with the maximum temperature reached at the surface of the furnace and the average heating rate for the measuring points 7,8 and 9 , located in the central region of the surface of the furnace. The equations presented by the F test was significant $(p<0.05)$.

baixas em relação ao resto do forno. O sistema tem ausência de cúpula ou cobertura, sendo o forno totalmente aberto, com isso perde calor para o ambiente com grande facilidade, sendo altamente relacionado com as variáveis ambientais, o que não é interessante no processo de queima das cerâmicas.

De acordo com Bouth (2008) a temperatura de sinterização ideal fica entre $900^{\circ} \mathrm{C}$ a $950{ }^{\circ} \mathrm{C}$ para obter um produto de boa qualidade, temperaturas essas atingida nas camadas mais baixas do forno. Com isso, as telhas localizadas nas camadas superiores do forno, quando a queima é encerrada, ainda estão submetidas a temperaturas muito baixas. De acordo com EELA, (2012), o ideal é em torno de $850^{\circ} \mathrm{C}$ ou mais.

Já no trabalho de Carvalho (2001) os melhores resultados obtidos no tempo de queima foram com 120 minutos a 180 minutos de esquento e 480 minutos a 600 minutos de queima, sendo o ciclo de produção completo de um forno do tipo "caipira" com uma média de duração de 780, "não incluindo o tempo de resfriamento".

De acordo com o do relatório da EELA (2012) o ciclo de queima costuma ser relativamente curto, pode-se ter um esquente (pré-aquecimento) de 2 a 12 horas, 
de acordo com a umidade da carga e da lenha, a queima de 7 a 12 horas (dependendo do tipo lenha), e o resfriamento entre 20 e 24 horas. Assim, um ciclo completo deve se situar na média em 38 horas, ou seja, 2280 minutos total.

As temperaturas na superfície dos fornos foram baixas, o que determinou baixa produção de peças de primeira qualidade, situando-se em torno de 5 a $22 \%$ em função da deficiência da sinterização completa.

O ciclo de queima observado nesse trabalho foi no máximo de 900 minutos o qual difere dos resultados observados pelo EELA (2012) que encontrou, em média, tempo total do processo equivalente a 38 horas ou 2280 minutos. Provavelmente a forma empírica de controle do processo promove variações consideráveis no tempo total do processo.

O tratamento 4 obteve a menor percentagens de telha de primeira qualidade variando de $5 \%$ a $20 \%$. Apesar da heterogeneidade da temperatura houve uma produção significativa de telha de primeira qualidade. A região onde se produz a maior quantidade é no centro do forno localizado entre o $2^{\circ}$ e $3^{\circ}$ piso de telhas, nunca nas laterais nem na superfície do forno.

Os resultados encontrados foram de acordo com os de Andrade (2009) e Baccelli Junior (2010), que dizem que a produção de telha de primeira qualidade chega até $20 \%$. O relatório EELA (2012), descreve que se a queima for bem controlada em o forno do tipo "caipira" a quantidade de telhas de primeira qualidade pode chegar até $35 \%$, quantidade essa que não foi observada em nenhum tratamento.

A produção de telha de segunda qualidade teve uma porcentagem média de $70 \%$ à $85 \%$ entre os 4 tratamentos estudados, sendo que o tratamento 1 obteve $85 \%$. Observa-se, portanto, que houve maior produção de telha de segunda qualidade.

De acordo Andrade (2009) e Baccelli Junior (2010) a produção de telha de segunda qualidade, em forno caipira, fica numa média de $60 \%$ a $80 \%$.

A produção de telha de terceira qualidade foi muito pequena ficando entre $1 \%$ a $3,5 \%$. O tratamento 4 obteve a maior porcentagem de telha de terceira qualidade $(3,5 \%)$. As telhas de terceira qualidade são localizadas em maior parte no quarto piso, onde recebem a chama direta das câmaras de combustão, ocasionando assim uma sinterização excessiva, promovendo quebra, empenamento, rachaduras, trincas ou coloração escura telhas.

A produção de telhas mal queimadas ocorre quando a telha não atinge a temperatura de sinterização suficiente para atingir as propriedades adequadas exigidas pelas normas da ABNT NBR 15.270. Essas telhas são encontras geralmente na lateral do forno ou superfície do forno, onde atingem baixas temperaturas, elas voltam para o forno novamente para serem queimadas e atingir o ponto de sinterização adequado, só que após a queima elas não são mais consideradas telhas de primeira qualidade, são classificadas como segunda ou terceira qualidade. A produção dessas telhas foi de $1 \%$ a $6 \%$, uma média de 380 a 3.000 telhas por queima. Os tratamentos 1 e 4 obtiveram a menor produção de telhas mal queimadas (1\% a $3 \%$ ) e os tratamentos 2 e 3 obtiveram maior produção (acima de 3\%).

A quantidade de telhas quebradas ficou em torno de $3 \%$ a $16 \%$, atingindo até 6.000 mil telhas numa queima, uma quantidade muito grande de desperdício. Esses resultados foram semelhantes aos encontrados por Carvalho (2001), que cita a porcentagem de perdas em torno de $2 \%$ a $15 \%$.

O controle do tempo de queima e da temperatura alcançado influencia diretamente na qualidade das telhas, pois as peças queimadas durante muito tempo em temperaturas muito altas ficam sinterizadas em excesso. Por outro lado, temperaturas baixas ou tempos de queima muito curtos podem determinar peças cruas.

As temperaturas e as taxas de aquecimento alcançadas foram heterogêneas nos quatro tratamentos. No tratamento 4 observa-se uma maior porcentagem de telha de primeira qualidade, com $30 \%$ na terceira repetição, atingindo a temperatura máxima de $50^{\circ} \mathrm{C}$. Os demais tratamentos obtiveram porcentagens entre $10 \%$ a $22 \%$, sendo o tratamento 1 o que teve maior diferença entre as temperaturas e a taxa de aquecimento nas queimas.

O tratamento 4 obteve a maior porcentagens de telha de primeira em relação aos outros tratamentos, mesmo atingindo baixa temperatura. A curva de temperatura ideal, que proporciona a melhor qualidade dos produtos cerâmicos foi a do tratamento 1 que obteve uma média de $18,66 \%$ de produto de primeira qualidade, atingindo temperatura mínima de queima de $100^{\circ} \mathrm{C}$ e máxima de $400^{\circ} \mathrm{C}$.

Revista Árvore, Viçosa-MG, v.39, n.5, p.963-972, 2015 


\section{CONCLUSÕES}

Com base nos resultados obtidos, conclui-se que:

- O forno do tipo "caipira" apresentou perfil térmico heterogêneo, verificou-se que houve o encerramento do processo antes de se atingir uma temperatura adequada à produção de maior quantidade de telhas de melhor qualidade.

- O parâmetro do fio foi significativo para todos os tratamentos, mas a variação de oscilações foi diferenciada entre os tratamentos, demonstrando que o fio não deve ser usado de forma genérica e exclusivamente como o único critério para finalização do processo de queimas.

- A parte central do forno foi à área que atingiu maiores temperaturas e de maneira mais homogênea, havendo assim a maior concentração de produtos de primeira qualidade.

- Recomendam-se aumento na espessura das paredes do forno, juntamente com isolantes e utilização de grelhas para suspensão das cerâmicas, visando melhorar na eficiência térmica

\section{AGRADECIMENTOS}

À Unidade Acadêmica Especializada em Ciências Agrárias / Escola Agrícola de Jundiaí - Universidade Federal do Rio Grande do Norte, à Fundação de Apoio à Pesquisa do Estado do Rio Grande do Norte (FAPERN), a Cerâmica Esperança, CNPq, CAPES e Embrapa Florestas.

\section{REFERÊNCIAS}

ANDRADE, F.L.F. Caracterização de materia prima de formulaçao de massas cerâmicas para telha na Rgião do Seridó-RN. 2009. Dissertação (Mestrado em Engenharia Mecânica) Universidade Federal do RioGrande do Norte, Natal, 2009.

\section{ASSOCIAÇÃO BRASILEIRA DE NORMAS TÉCNICAS - ABNT. NBR 15270:}

Componentes cerâmicos. Rio de Janeiro: 2005. $11 \mathrm{p}$.

BACCELli JÚNIOR, G. Avaliação do processo industrial da cerâmica vermelha na região do Seridó-RN. 2010. 200f. Tese (Doutorado em Engenharia Mecânica) - Universidade Federal do Rio Grande do Norte, Natal, 2010.

BOUTH, J.A.C. Manual de operações básicas na indústria de cerâmica vermelha. Natal: Fast Graf, 2008. 104p.

CARVAlho, O.O. Perfil da indústria cerâmica vermelha do Rio Grande do Norte. Natal: SENAI, 2001. CD-ROM.

EFICIÊNCIA ENERGÉTICA EN LADRILLERAS ARTESANALES - EELA. Programa de eficiência energética en ladrilleras artesanales de Ameria Latina para mitigar el cambio climatico. Rio de Janeiro: Ministério da Ciência, Tecnologia e Inovação, 2012. 16p.

FREITAS, F.C.G. Balanço energético de um forno túnel de cerâmica estrutural convertido de lenha para gás natural. 2007. 90f. Tese (Doutorado em Pesquisa e Desenvolvimento de Tecnologias Regionais) Universidade Federal do Rio Grande do Norte, Natal, 2007.

QUEIROZ, A.B. et al. Conservação de energia no setor industrial: cerâmica estrutural. [S.L.] Superintendência do desenvolvimento do Nordeste- SUDENE e fundação Instituto Tecnológico do Estado do Pernambuco/ITEP, 1988.

SILVEIRA, L.H.C.; REZENDE, A.V.; VALE, A.T. Teor de umidade e densidade básica da madeira de nove espécies comerciais amazônicas. Acta Amazonica, v.43, n.2, p.179-184, 2013.

VITAL, B.R. Métodos de determinação de densidade da madeira. Viçosa, MG: SIF, 1984. 21p. (Boletim Técnico, 1) 